\title{
Assessing effects of aerobic and anaerobic conditions on phosphorus sorption and retention capacity of water treatment residuals
}

\author{
Ian W Oliver ${ }^{\mathrm{a} *}$, Cameron D Grant ${ }^{\mathrm{b}}$ and Robert S Murray ${ }^{\mathrm{a}}$ \\ a The University of Adelaide, School of Earth \& Environmental Sciences, SA 5005, Australia \\ ${ }^{\mathrm{b}}$ The University of Adelaide, School of Agriculture, Food \& Wine, SA 5005, Australia \\ * corresponding author email: lan.Oliver@alumni.adelaide.edu.au
}

\begin{abstract}
Water treatment residuals (WTRs) are the by-products of drinking water clarification processes, whereby chemical flocculants such as alum or ferric chloride are added to raw water to remove suspended clay particles, organic matter and other materials and impurities. Previous studies have identified a strong phosphorus (P) fixing capacity of WTRs which has led to experimentation with their use as $\mathrm{P}$-sorbing materials for controlling $\mathrm{P}$ discharges from agricultural and forestry land. However, the P-fixing capacity of WTRs and its capacity to retain sorbed P under anaerobic conditions has yet to be fully demonstrated, which is an issue that must be addressed for WTR field applications. This study therefore examined the capacity of WTRs to retain sorbed P and sorb further additional $P$ from aqueous solution under both aerobic and anaerobic conditions. An innovative, low cost apparatus was constructed and successfully used to rapidly establish anoxic conditions in anaerobic treatments. The results showed that even in treatments with initial solution $P$ concentrations set at $100 \mathrm{mg} \mathrm{I}^{-1}$, soluble reactive $\mathrm{P}$ concentrations rapidly fell to negligible levels (due to sorption by WTRs), while total P (i.e. dissolved + particulate and colloidal P) was less than 3 $\mathrm{mg} \mathrm{l}^{-1}$. This equated to an added $\mathrm{P}$ retention rate of $>98 \%$ regardless of anaerobic or aerobic status, indicating that WTRs are able to sorb and retain P in both aerobic and anaerobic conditions.
\end{abstract}

Key words: Phosphorus control; Eutrophication; Anoxic conditions; Redox potential; Eh

\section{Introduction}

Water treatment residuals (WTRs) are the by-products of drinking water clarification processes carried out at water treatment facilities. Chemical flocculants, most commonly alum $\left(\mathrm{Al}_{2}\left(\mathrm{SO}_{4}\right)_{3}\right)$, or ferric chloride $\left(\mathrm{FeCl}_{3}\right)$, are added to raw water from a reservoir to coagulate and flocculate suspended clay particles, organic matter, and other materials (Graveland et al., 1993). Other additives, such as lime $\left(\mathrm{CaCO}_{3}\right)$, polyelectrolytes and activated carbon, may also be added to aid flocculation (Lehmann and Palmer, 1995). The flocculated material settles to the base of the treatment tanks. This material is removed and transferred to evaporation lagoons or mechanical presses for drying. The resulting product is a 'sludge' consisting of highly disordered clay minerals, organic matter, and precipitates of aluminium and iron hydroxides (Bugbee and Frink, 1985). 
Disposal of WTRs has generally been achieved by burial (landfill) or via application to farm or forestry land. Such land application has been routinely conducted in the USA for over 50 years (Elliot and Dempsey 1991), and studies in such areas have revealed no evidence of aluminium (or other) toxicity in any plant or animal species tested (Grabarek and Krug, 1987; Geertsema et al., 1994; Lucas et al., 1994). Indeed, other studies have shown that metals present in WTR are generally in non-labile and non-leachable forms that do not pose a toxic threat to organisms (Bugbee and Frink, 1985; Elliot and Singer, 1988; Cugley, 1994; Abdullah et al., 1995; Ahmed et al., 1998; Mahdy et al., 2008; Lombi et al., 2010). Many benefits to soil have been attributed to application of WTRs, including improved soil aggregation, aggregate stability, water retention, porosity and pH (e.g. Rengasamy et al., 1980; Che et al., 1988). However, many of the studies listed above noted fixation of phosphorus $(\mathrm{P})$ by WTRs, revealing a $\mathrm{P}$ sorbing capacity that could be used in the field to reduce the amount of $P$ entering water bodies and so help mitigate eutrophication ( $P$ is often the limiting nutrient controlling eutrophication rates in freshwater systems).

The P fixing capacity of WTRs has since been confirmed, presenting an economically viable means of controlling diffuse inputs of $\mathrm{P}$ which would be of particular value in developing countries where access to other products may be limited. For example, Basta et al. (1996) applied WTRs to soils treated with poultry manure and successfully reduced $P$ in run-off by more than $50 \%$. The same degree of $\mathrm{P}$ retention has been demonstrated in other, more recent studies (Agyin-Birikorang et al., 2007; Oladeji et al., 2007; Oladeji et al., 2008). In addition, Macks and co-workers (Macks, 1997; Macks et al., 1998) have shown that WTRs could be used to successfully remove $P$ from agricultural waste waters. The mechanisms of $P$ retention within WTRs include sorption and precipitation and have been investigated and described by Ippolito et al. (2003).

Based on these previous investigations it is possible to envisage various beneficial field applications of WTRs, either enacted separately or in combination, that could achieve P control in landscapes while simultaneously facilitating disposal of a waste product:

(1) broadcasting on soil; (2) placement in concentrated buffer strips (i.e. around water bodies and paddock boundaries); (3) ploughing into surface soil; (4) placement into vertical trenches and (5) use as a basin liner in effluent dams (Figure 1). 
However, before such field application of WTRs can be recommended, the effects of changes in redox status on $\mathrm{P}$ retention by the material must be determined. This is crucially important because many soils have been shown to release $P$ under anaerobic conditions, mostly as a result of reduction and dissolution of iron[III] (Savant and Ellis, 1964; Ponnamperuma, 1972; Hossner et al., 1973; Peaslee and Phillips, 1981; Vadas and Sims, 1998). This study aimed to determine the effects of anaerobic and aerobic conditions on the $P$ sorption and retention of WTRs.

\section{Methods}

\subsection{Water treatment Residuals (WTRs)}

Water treatment residuals (WTRs) produced at the Morgan Water Treatment Plant (Morgan, South Australia) with ferric chloride $\left(\mathrm{FeCl}_{3}\right)$ as the principal flocculant were selected for use in the study. Following the theory that iron reduction would be a key mechanism responsible for any anaerobic $\mathrm{P}$ release, ferric WTRs were selected in preference to aluminium-based residuals because of the higher iron content as this was expected to make the effects of anaerobic conditions more pronounced. An aggregate size range of 2 to $5 \mathrm{~mm}$ was selected, as this provided a compromise between the two important experimental issues of maximising surface area for reaction and allowing adequate solution movement through WTR samples. In addition, it has been shown that the material remains physically stable in this size range (Macks, 1997). The physico-chemical properties of the WTRs assessed are presented in Table 1.

\subsection{Verifying the presence of viable anaerobic microbes in WTRs}

In the expectation that microbial processes may also contribute to any reductive dissolution of iron and $\mathrm{P}$ from field-applied WTRs, an assessment was made to verify that adequate populations of anaerobic microbes (strict or facultative) were present in the materials tested. An anaerobic growth medium was prepared by mixing $23.5 \mathrm{~g}$ Brain-Heart Infusion (OXOID) with $5 \mathrm{~g}$ yeast extract (BIOFERM) and $500 \mathrm{ml}$ deionised water. The mixture was sterilised by autoclaving it at $121^{\circ} \mathrm{C}$ for 15 minutes. While cooling, the agar solution was treated with $50 \mathrm{mg}$ cyclohexamide (an antifungal agent, applied in a methanol solution) and was then mixed and poured into agar plates. A $10 \mathrm{~g}$ sample of WTRs was mixed with sterilised $0.09 \% \mathrm{NaCl}$ solution, to a total volume of $100 \mathrm{ml}$ (i.e. a $10^{-1}$ dilution of the WTRs, w/v). A suspension was formed by mixing the solution on a vortex mixer, from which the following dilutions (w/v) were prepared: $10^{-2}, 10^{-3}, 10^{-4}$ and $10^{-5}$. Samples $(0.1 \mathrm{ml})$ of each dilution were added to separate agar plates $(n=3)$. The plates were then placed in GAS-PACK 
DOI: 10.1016/j.jenvman.2010.11.016 (this file includes supplementary information and 2015 corrigendum)

anaerobic gas chambers and incubated at $30^{\circ} \mathrm{C}$ for six days, after which the number of microbial colony-forming units $(c f u)$ on each plate was counted and the number per gram WTR calculated. The results (using the mean of the $10^{-2}$ dilutions) indicated that the number of anaerobe $\mathrm{cfu} \mathrm{g}^{-1}$ WTR was $24500 \pm 700$, which is within the range commonly observed in soil (i.e. $10^{3}$ to $10^{5} \mathrm{cfu} \mathrm{g}^{-1}$ soil; Richards, 1987).

\subsection{Phosphorus-loading of WTRs}

To investigate the potential release of sorbed $P$, it was first necessary to load P onto the WTRs. A $10 \mathrm{mg} \mathrm{l}^{-1} \mathrm{P}$ solution (prepared from $\mathrm{KH}_{2} \mathrm{PO}_{4}$ ) was used for this. The apparatus constructed for exposing WTRs to the $P$ solution consisted of a perspex cylinder (64 mm id, $500 \mathrm{~mm}$ length), sealable at both ends with rubber stoppers, that was equipped with a solution inlet/outlet tube at either end (Figure 2). Fine plastic mesh was fixed over the inlet/outlet tubes (inside the cylinder) so that WTR aggregates could not enter the tubes. The cylinder was filled to capacity with WTRs $(1.1 \mathrm{~kg})$ for exposure to the $\mathrm{P}$ solution. A $10 \mathrm{I}$ canister served as the $\mathrm{P}$ solution reservoir, and this was raised above the height of the cylinder to establish a positive pressure. To ensure the aerobic state of the solution, it was passed through a wide-mouth funnel that was 3/4 filled with glass beads. The solution was delivered from the funnel to the bottom inlet tube of the cylinder (which was in an upright position, Figure 2) through plastic tubing. It then flowed up through the WTRs and out of the cylinder via the outlet tube at the top (at approximately $170 \mathrm{ml} \mathrm{min}^{-1}$ ). The out-flowing solution was collected, from which samples were taken and analysed colorimetrically for dissolved reactive $\mathrm{P}$ concentration (see section 2.6).

Each time the 10 I reservoir was exhausted, the cylinder was disconnected from the plastic tubing, inverted, and then reconnected. The reservoir was then restocked with fresh solution, and the Ploading process repeated. The cylinder was inverted between 'runs' of the reservoir to promote a more uniform loading of $P$ throughout the entire mass of material (i.e. to prevent WTRs at one end from adsorbing $P$ to a greater extent than that at the other). Five runs of the reservoir were completed, so that a total volume of 50 I was passed through the $1.1 \mathrm{~kg}$ of WTRs. From the known volume and starting concentration of each run (10 I and $10 \mathrm{mg} \mathrm{I}^{-1}$, respectively) and the concentrations measured in the out-flowing solutions, the total amount of $P$ sorbed by the WTRs was calculated. This resulted in an added $P$ concentration of $211 \mathrm{mg} \mathrm{kg}^{-1}$. A control batch of WTRs was also prepared using deionised water in place of the $\mathrm{P}$ solution. The P-loaded and control WTRs were then placed in trays to air-dry at room temperature $\left(20\right.$ to $\left.23^{\circ} \mathrm{C}\right)$ for three days, after which 
DOI: 10.1016/j.jenvman.2010.11.016 (this file includes supplementary information and 2015 corrigendum)

gentle hand-mixing was carried out to ensure uniformity of sub-samples ( $\mathrm{P}$-loaded and control batches of WTRs were kept entirely separate).

\subsection{Treatments imposed on WTRs: variable P concentrations and aerobic vs anaerobic conditions}

To determine its capacity to retain sorbed $P$ and further sorb additional $P$ under both aerobic and anaerobic conditions, $50 \mathrm{~g}$ subsamples $(\mathrm{n}=3)$ of the WTRs were placed in $500 \mathrm{ml}$ Erlenmeyer flasks and exposed to $190 \mathrm{ml}$ of one of three $\mathrm{P}$ solutions $\left(0,10\right.$ or $\left.100 \mathrm{mg} \mathrm{l}^{-1}\right)$ for 31 days under either anaerobic or aerobic conditions (Table 2). $10 \mathrm{ml}$ of a sugar solution containing $2.5 \mathrm{~g}$ glucose (prepared in 0,10 , and $100 \mathrm{mg} \mathrm{l}^{-1} \mathrm{P}$ solutions as appropriate) was added to each unit in order to prime microbial activity.

Aerobic conditions were maintained by leaving flasks unsealed, allowing free air exchange between flask and atmosphere. Anaerobic conditions were imposed by sealing flasks with rubber stoppers that had been equipped with gas inlet and outlet tubes (Figure 3 and supplementary information), through which argon (Ar) gas was continually pumped. The $\operatorname{Ar}$ gas was pumped into the supernatant solution above the WTRs, at approximately $5 \mathrm{ml} \mathrm{min}^{-1}$, through a gas manifold system (constructed from plastic tubing) that connected the inlet tubes of all anaerobic flasks to a single Ar supply (Figure 3). The narrow gas outlet tube of each flask, although sealable when required, remained open to allow the escape of Ar gas. All flasks were placed on a flat-bed orbital shaker set to a speed that caused gentle solution movement but not movement of WTR aggregates (Figure 3). This step was taken so that the solution would continually move through the entire $50 \mathrm{~g}$ sample. Mild agitation would also promote the diffusion of oxygen into the solution of aerobic units, so maintaining their aerobic status. Flasks were shaken in this manner throughout the 31-day experiment, with shaking only briefly halted to allow sampling (after which it was immediately resumed).

\subsection{Supernatant sampling and redox (Eh) status assessment during the 31 day exposure}

At 2, 5, 10, 14, 20 and 31 days, a $3 \mathrm{ml}$ sample of the supernatant solution was taken from each flask, filtered through a $0.45 \mu \mathrm{m}$ cellulose acetate filter (Millipore) and analysed for soluble reactive $\mathrm{P}$ (section 2.6). The $\mathrm{pH}$ and reduction-oxidation (redox) potential (Eh) were also measured during sampling (and at time 0), with pH measured using a Hanna $\mathrm{H} 18424$ microcomputer $\mathrm{pH}$ meter and Eh measured using a platinum $(\mathrm{Pt})$ electrode and a silver-sliver chloride $(\mathrm{Ag}-\mathrm{AgCl})$ reference 
DOI: 10.1016/j.jenvman.2010.11.016 (this file includes supplementary information and 2015 corrigendum)

electrode connected to a Hanna HI 8521 volt meter. The observed voltage values were corrected to Eh (Christian and O'Reilly, 1986) and the accuracy of Eh measurements was validated by measuring the Eh of freshly prepared Zobell's solution (Langmuir, 1971; Nordstrom, 1977) at each measurement time, with readings throughout the experiment always being within the stated correct range for the ambient temperature (Langmuir, 1971; Nordstrom, 1977). The accuracy of Eh measurements was further confirmed by periodically repeating individual measurements with alternative Pt electrodes and a separate independent volt meter (Fluke 73 Multimeter).

For aerobic treatments, each sample was obtained by inserting a pipettor into the open flask and extracting the $3 \mathrm{ml}$. Aerobic treatments were also weighed during sampling to determine any mass lost via evaporation, which was replaced with deionised water (after Eh measurements had been completed).

For anaerobic treatments, additional steps were taken to reduce exposure to air during sampling: the gas outlet tube of each flask was sealed before removal from the Ar gas supply, and the electrodes were fitted to a rubber stopper so that air could not enter the flasks once the stopper was in place for the Eh and $\mathrm{pH}$ measurements. Therefore, except for the short time it took to extract the $3 \mathrm{ml}$ sample and exchange rubber stoppers (i.e. treatment stopper for the electrode holding stopper), the anaerobic treatments remained isolated from atmospheric air. The exposure time was very short ( $<1$ minute) and, as Ar is heavier than air and would form a protective 'blanket' over the WTR and solution that would exclude oxygen, contamination from atmospheric air was considered to be negligible (as confirmed by Eh readings). The anaerobic treatments were reconnected to the Ar supply immediately after sampling.

\subsection{Chemical analysis}

All samples collected during the 31 day exposure, as well as samples from the inlet and outlet flows of the $\mathrm{P}$ loading solution described in section 2.3 , were analysed colorimetrically for soluble reactive P concentrations following the ascorbic acid method of Murphy and Riley (1962) and using a Unicam S.P. 600 Spectrophotometer. Throughout the experiment a number of selected samples were also analysed for soluble reactive P using a Shimadzu UV-Visible Spectrophotometer (UV1601) as a further check on measurement accuracy. Iron (II) and iron (III) concentrations were also determined in each solution using colorimetric methods, following the phenanthroline method for iron (II) (Eaton et al., 1995) and the modified phenanthroline method for total iron (Buurman et al., 1996). 
After the 31 day test period, all sample solutions were also analysed for total $\mathrm{P}$ and organic carbon $(\mathrm{OC})$. For total $\mathrm{P}$, a $25 \mathrm{ml}$ aliquot (non-filtered) was taken from each replicate and evaporated to dryness, digested in 6:1 nitric acid-perchloric acid and analysed for total $\mathrm{P}$ following the ascorbic acid method described by Eaton et al. (1995). For organic carbon, the remaining sample was filtered through a Whatman \#42 filter paper $(2.5 \mu \mathrm{m}$ pore diameter) and a $25 \mathrm{ml}$ aliquot was evaporated over-night, at $105^{\circ} \mathrm{C}$, with the dry residue analysed for organic carbon the following day using the Walkley-Black wet-oxidation method (Buurman et al., 1996).

Statistical analysis of differences between treatments and groups of treatments was performed via Mann-Whitney $U$, Kruskal-Wallis and analysis of variance (ANOVA) tests using the software packages Analyse-it and Microsoft Excel. Significance was assessed at the 95\% confidence level (i.e. $p<0.05$ ).

\section{Results and discussion}

\subsection{Redox potential (Eh) and $\mathrm{pH}$ status of samples during the 31 day exposure}

Confirming the effectiveness of the apparatus designed and constructed for the experiment, all anaerobic units experienced reducing conditions (i.e. Eh < $350 \mathrm{mV}$; Patrick and Mahapatra, 1968) throughout the 31 day treatment period while all aerobic units maintained Eh values indicative of oxidising conditions (Figure 4). The anaerobic treatments had rapid decreases in Eh to values approaching $-400 \mathrm{mV}$ within 2 days of commencement, which then stabilised at 0 to $100 \mathrm{mV}$ by day 10 where they remained for the rest of the experiment. This reflected a rapid anaerobic microbial decomposition of the added glucose, which created an intensely reducing environment for the first days of the experiment. As the added glucose became depleted, the system equilibrated to an Eh reflecting a steady rate of microbial activity and the Eh poising capacity of the WTRs (from iron, manganese and nitrate contents) under anaerobic conditions. The anoxic status of the anaerobic treatments was also confirmed by the elevated supernatant iron (II) concentrations observed in all anaerobic treatments (i.e. 50 to $400 \mathrm{mg} \mathrm{l}^{-1}$ : see supplementary information). 
Regarding $\mathrm{pH}$, the treatments with $100 \mathrm{mg} \mathrm{l}^{-1} \mathrm{P}$ solutions had initial $\mathrm{pH}$ values of $6.2 \pm 0.02$, while those with $10 \mathrm{mg} \mathrm{l}^{-1} \mathrm{P}$ solutions had values of $6.5 \pm 0.03$ and the zero $\mathrm{P}$ treatments (and controls) had $\mathrm{pH}$ values of $6.7 \pm 0.03$. By the end of the 31 days, the $\mathrm{pH}$ in each of the anaerobic treatments had stabilised at $6.8 \pm 0.02$, while in each of the aerobic treatments the $\mathrm{pH}$ rose gradually and by day 15 had stabilised at $8.0 \pm 0.07$.

\subsection{Soluble reactive phosphorus}

The concentration of soluble reactive $P$ was less than $1 \mathrm{mg} \mathrm{l}^{-1}$ in the supernatant solution of every treatment from the first measurement after commencement (2 days contact), regardless of the starting $P$ concentration or Eh status (Figure 5). For treatments 1, 2, 4 and 5, the soluble reactive $P$ concentration was below $0.3 \mathrm{mg} \mathrm{l}^{-1}$ after day 5 , while for treatments 3 and $6\left(100 \mathrm{mg} \mathrm{l}^{-1}\right.$ starting concentration) concentrations were below $0.6 \mathrm{mg} \mathrm{l}^{-1}$ after 10 days and below $0.2 \mathrm{mg} \mathrm{l}^{-1}$ after 31 days (Figure 5). No significant differences were observed between aerobic or anaerobic treatments $(p>0.05$, ANOVA), confirming that anaerobic conditions did not reduce the sorbing or retention capacity of WTR during the 31-day study. Similarly, by day 31 no significant differences were found between control treatments and treatments involving P-loaded WTRs. The results demonstrate that the utility of WTRs for P management in the field would not be affected by redox status (i.e. areas subject to water logging, or application in submerged situations, would not have a reduced $\mathrm{P}$ management effect).

\subsection{Total $P$ and organic carbon}

While supernatant total $\mathrm{P}$ concentrations were always below $3 \mathrm{mg} \mathrm{l}^{-1}$ in all treatments, there was a significant difference (Mann-Whitney $U$ test) between aerobic and anaerobic treatments; with anaerobic treatments having greater total $P$ concentrations (Figure 6). However, there was no significant difference in total $\mathrm{P}$ concentration amongst the anaerobic treatments (Kruskal- Wallis test), regardless of starting $\mathrm{P}$ concentration. The same was true (i.e. no significant difference) amongst the aerobic treatments. Because soluble $\mathrm{P}$ concentrations in all treatments were very low $\left(<1 \mathrm{mg} \mathrm{l}^{-1}\right)$, the additional total $\mathrm{P}$ in the anaerobic treatments (up to $\left.2.0 \pm 0.5 \mathrm{mg} \mathrm{l}^{-1}\right)$ must be present as particulate or colloidal material. 
Organic carbon concentrations were also significantly higher in anaerobic treatments (MannWhitney $U$ test, Figure 6), but there were no significant differences amongst the anaerobic treatments (i.e. OC concentrations in treatments 1, 2 and 3 were statistically equivalent). The increased $\mathrm{OC}$ and total $\mathrm{P}$ concentrations in anaerobic treatments is suggestive of a link, indicating the strong probability that the particulate or colloidal $P$ is at least partially associated with OC. Such associations are common in soils, as particulate and colloidal $O C$ is known to be a transport vector of P (e.g. Frossard et al., 1989; Haygarth and Jarvis, 1997; Heathwaite, 1997; Gburek and Sharpley, 1998) as well as other nutrients and contaminants (e.g. Graham et al., 2008). Much higher iron (II) concentrations were observed in the anaerobic treatments (i.e. $\sim 50$ to $400 \mathrm{mg} \mathrm{I}^{-1}$ compared to $<1 \mathrm{mg} \mathrm{I}^{-1}$; see supplementary material) and so a portion of the particulate $P$ is also likely to be associated with iron complexes, either discretely or intimately associated with OC, that were released upon partial reductive dissolution of ferric constituents of WTRs. Nevertheless, it must be kept in mind that even the highest total $P$ concentration observed amongst the supernatant solutions $\left(2.0 \pm 0.5 \mathrm{mg} \mathrm{l}^{-1}\right.$, Treatment 3 , Figure 6$)$ represented merely $1.3 \%$ of the added $P$ (i.e. P loaded onto the WTRs + solution P) and only $0.4 \%$ of the total P (i.e. native P, Table 1 , plus added $\mathrm{P})$. Therefore, when the amount of added $\mathrm{P}$ retained is calculated on a mg kg-1 basis, the WTRs examined in this study were able to retain up to $\sim 400 \mathrm{mg} \mathrm{kg}^{-1}$ added $\mathrm{P}$ under both aerobic and anaerobic conditions, with no sign of saturation having been reached.

\section{Conclusions}

The apparatus designed and constructed in this study for creating anaerobic conditions proved extremely effective, with all replicates of all anaerobic treatments having rapidly established the desired anaerobic state. This apparatus was inexpensive to build and required no technologically advanced components and thus would be particularly suited for use in laboratories with tight budgetary restraints (including those in developing countries).

This investigation found that water treatment residuals (WTRs) retained sorbed $P$ regardless of aeration status or ambient solution $\mathrm{P}$ concentration for the entire duration of the study (31 days). Further, the study found that WTRs maintained the capacity to fix large amounts of additional P (up to $400 \mathrm{mg} \mathrm{kg}^{-1}$ ) under both aerobic and extreme anaerobic conditions (i.e. continual saturation under an Ar atmosphere). Small amounts of particulate or colloidal $\mathrm{P}$, associated with iron and/or organic constituents, were present in solutions at the completion of the study but the amounts 
Oliver IW, Grant CD, Murray RS. Assessing effects of aerobic and anaerobic conditions on phosphorus sorption and retention capacity of water treatment residuals. Journal of Environmental Management 2011; 92: 960-966.

DOI: 10.1016/j.jenvman.2010.11.016 (this file includes supplementary information and 2015 corrigendum)

represented only $1.3 \%$ of the added $\mathrm{P}$ or $0.4 \%$ of the total $\mathrm{P}$ within the WTRs. This indicates that WTRs placed in the field are unlikely to release $P$ in environmentally significant amounts even when under anaerobic conditions, thus use of WTR for P management in catchments need not be limited to surface applications only.

\section{Acknowledgements}

We thank Colin Rivers for his contributions toward the design and construction of the apparatus used in this study and for additional technical support. We also thank Andrew Dowley for providing platinum electrodes and advice on their use.

\section{References}

Abdullah, M.P., Baba, I., Sarmani, S., Erdawati., 1995. Distribution of Aluminium from alum sludge in water and sediment. Mar. Freshw. Res. 46, 159-165.

Agyin-Birikorang, S., O'Connor, G.A., Jacobs, L.W., Makris, K.C., Brinton, S.R., 2007. Long-term phosphorus immobilization by a drinking water treatment residual. J. Environ. Qual. 36, 316-323.

Ahmed, M., Grant, C.D., Oades, J.M., Tarrant, P., 1998. Use of water treatment sludge - Lability of aluminium in soils. Water: J. Aus. Wat. Wastewater Assoc. 25, 11-15.

Basta, N., Storm, D.E., Peters, J.,1996. Use of alum hydrosolids (alum sludge) to reduce nutrient runoff from agricultural land treated with animal manures to protect surface water quality. Oklahoma State University, Research report. Stillwater, Oklahoma.

Bugbee, G.T., Frink, C.R., 1985. Alum sludge as a soil amendment: Effects on soil properties and plant growth. Connecticut Agric. Exp. Station Bull. 827.

Buurman, P., van Lagen, B., Velthorst, E.J., 1996. Manual for soil and water analysis. Backhuys Publishers, Leiden.

Che, M.D., Logan, T.J., Traina, S.J., Bigham, J.M., 1988. Properties of water treatment lime sludges and their effectiveness as agricultural limestone substitutes. J. Wat. Pollut. Con. Fed. (WPCF) 60, 674-680.

Christian, G.D., O'Reilly, J.E., 1986. Instrumental Analysis. Allyn and Bacon, Inc.: Boston.

Cugley, J., 1994. Release of aluminium from alum sludge - Implications for sludge use. US Environment Protection Authority.

Eaton, A.D., Clesceri, L.S., Greenberg, A.E., 1995. Standard methods for the examination of water and wastewater. American Public Health Association. American Water Works Association. Water Environment Federation: Washington, DC. 
DOI: 10.1016/j.jenvman.2010.11.016 (this file includes supplementary information and 2015 corrigendum)

Elliot, H.A., Dempsey, B.A., 1991. Agronomic effects of land application of water treatment sludges. J. Am. Wat. Works Assoc. 83, 126-131.

Elliot, H.A., Singer, L.M., 1988. Effect of water treatment sludge on growth and elemental composition of tomato (Lycopersicon esculentum) shoots. Commun. Soil Sci. Plant Anal. 19, 345 354.

Frossard, E., Stewart, J.W.B., St. Arnaud, R.J., 1989. Distribution and mobility of phosphorus in grassland and forest soils of Saskatchewan. Canad. J. Soil Sci. 69, 401-416.

Gburek, W.J., Sharpley, A.N., 1998. Hydrologic controls on phosphorus loss from upland agricultural watersheds. J. Environ. Qual. 27, 267-277.

Geertsema, W.S., Knocke, W.R., Novak, J.T., Dove, D., 1994. Long-term effects of sludge application to land. J. Am. Wat. Works Assoc. 86, 64-74.

Grabarek, R.J., Krug, E.C., 1987. Silvicultural application of alum sludge. J. Am. Wat. Works Assoc. 74, 84-88.

Graham, M.C., Oliver, I.W., MacKenzie, A.B., Ellam, R.M., Farmer, J.G., 2008. An integrated colloid fractionation approach applied to the characterisation of porewater uranium-humic interactions at a depleted uranium contaminated site. Sci. Tot. Environ. 404, 207-217.

Graveland, A., Heijman, S.G.J., Koppers, H.M.M., 1993. Integral approach of water treatment residuals. Wat. Supp. 12, SS 3.1- SS3.6.

Haygarth, P.M., Jarvis, S.C., 1997. Soil-derived phosphorus in surface run-off from grazed grassland, in: Tunney, H., Carton, O.T., Brookes, P.C., Johnston, A.E. (Eds.), Phosphorus Loss from Soil to Water. CAB International, New York, pp. 351-354.

Heathwaite, A.L., 1997. Sources and pathways of phosphorus loss from agriculture, in: Tunney, H., Carton, O.T., Brookes, P.C., Johnston, A.E. (Eds.), Phosphorus Loss from Soil to Water. CAB International, New York, pp. 205-224.

Hossner, L.R., Freeouf JA, Folsom BL, 1973. Solution P concentration and growth of rice (Oryza sativa L.) in flooded soils. Soil Sci. Soc. Am. Proc. 37, 405-408.

Ippolito, J.A., Barbarick, K.A., Heil, D.M., Chandler, J.P., Redente, E.F., 2003. Phosphorus retention mechanisms of a water treatment residual. J. Environ. Qual. 32, 1857-1864.

Langmuir, D., 1971. Eh-pH Determination, in: Carver, R. (Ed.), Procedures in sedimentary petrology, Wiley - Interscience, New York, pp. 597-634.

Lehmann, T.C., Palmer, N.T., 1995. Alum sludge treatment and disposal from Happy Valley Water Treatment Plant. Proc. 16th Fed. Conv. Aus. Wat. Wastewater Assoc. pp. 643-649.

Lombi, E., Stevens, D.P., McLaughlin, M.J., 2010. Effect of water treatment residuals on soil phosphorus, copper and aluminium availability and toxicity. Environ. Pollut. 158, 2110-2116. 
DOI: 10.1016/j.jenvman.2010.11.016 (this file includes supplementary information and 2015 corrigendum)

Lucas, J.B., Dillaha, T.A., Reneau, R.B., Novak, J.T., Knocke, W.R., 1994. Alum sludge land application and its effect on plant growth. J. Am. Waterworks Assoc. 86, 75-83.

Macks, S.P., 1997. Water treatment sludges and their use in removing phosphorus from contaminated water. Masters thesis, University of Adelaide, Department of Soil Science.

Macks, S.P., Grant, C.D., Murray, R.S., Drew, E.A., 1998. Phosphorus sorption by water treatment sludges. Proc. National Soils Conf. Aust. Soc. Soil Sci. Brisbane. pp. 93-99.

Mahdy, A.M., Elkhatib, E.A., Fathi, N.O., 2008. Drinking water treatment residuals as an amendment to alkaline soils: Effects on bioaccumulation of heavy metals and aluminum in corn plants. Plant Soil Environ. 54, 234-246.

Murphy, J., Riley, J.P., 1962. A modified single solution method for the determination of phosphate in natural waters. Analyt. Chim. Acta 27, 31-36.

Nordstrom, D.K., 1977. Thermochemical redox equilibria of Zobell's solution. Electrochim. Cosmochim. Acta 41, 1835-1841.

Oladeji, O.O., O'Connor, G.A., Brinton, S.R., 2008. Surface applied water treatment residuals affect bioavailable phosphorus losses in Florida sands. J. Environ. Man. 88, 1593-1600.

Oladeji, O.O., O'Connor, G.A., Sartain, J.B., Nair, V.D., 2007. Controlled application rate of water treatment residual for agronomic and environmental benefits. J. Environ. Qual. 36, 1715-1724.

Patrick, W.H., Jr., Mahapatra, I.C., 1968. Transformation and availability to rice of nitrogen and phosphorus in waterlogged soils. Adv. Agron. 20, 323-359.

Peaslee, D.E., Phillips, R.E., 1981. Phosphorus dissolution-desorption in relation to bioavailability and environmental pollution, in: Stelly M (Ed.), Chemistry in the soil environment - ASA special publication number 40. Am. Soc. Agron. \& Soil Sci. Soc. Am., Madison, Wisconsin, pp. 252-258.

Ponnamperuma, F.N., 1972. Chemistry of submerged soils. Adv. Agron. 24, 29-96.

Rengasamy, P., Oades, J.M., Hancock, T.W., 1980. Improvement of soil structure and plant growth by addition of alum sludge. Commun. Soil Sci. Plant Anal. 11, 533-545.

Richards, B.N., 1987. The Microbiology of Terrestrial Ecosystems. Longman Scientific \& Technical: New York.

Savant, N.K., Ellis, R., Jr,. 1964. Changes in redox potential and phosphorus availability in submerged soil. Soil Sci. 98, 388-394.

Vadas, P.A., Sims, J.T., 1998. Redox status, poultry litter, and phosphorus solubility in Atlantic Coastal Plain soils. Soil Sci. Soc. Am. J. 62, 1025-1034 
Oliver IW, Grant CD, Murray RS. Assessing effects of aerobic and anaerobic conditions on phosphorus sorption and retention capacity of water treatment residuals. Journal of Environmental Management 2011; 92: 960-966.

DOI: 10.1016/j.jenvman.2010.11.016 (this file includes supplementary information and 2015 corrigendum)

\section{FIGURES}

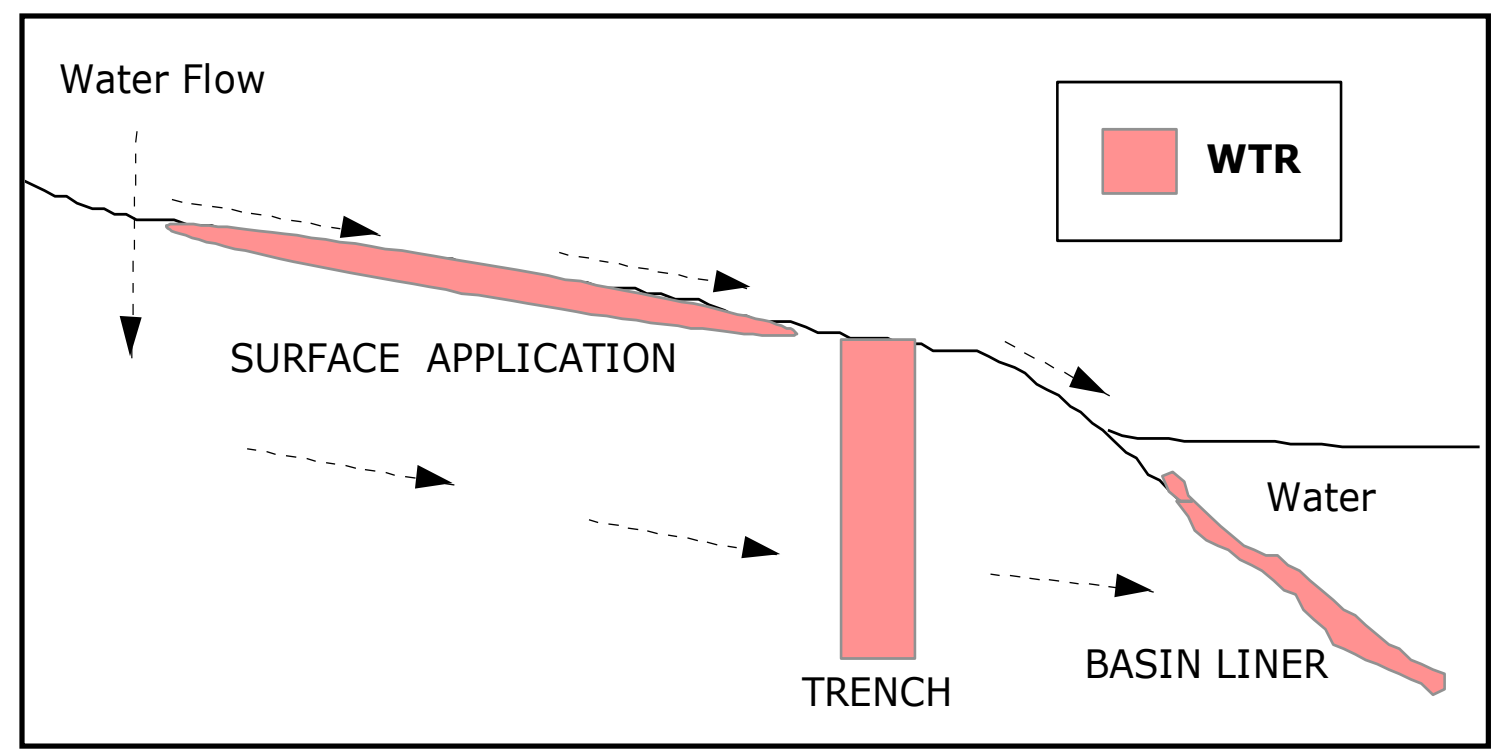

Figure 1. Potential field applications of WTRs for P management. 
Oliver IW, Grant CD, Murray RS. Assessing effects of aerobic and anaerobic conditions on phosphorus sorption and retention capacity of water treatment residuals. Journal of Environmental Management 2011; 92: 960-966.

DOI: 10.1016/j.jenvman.2010.11.016 (this file includes supplementary information and 2015 corrigendum)

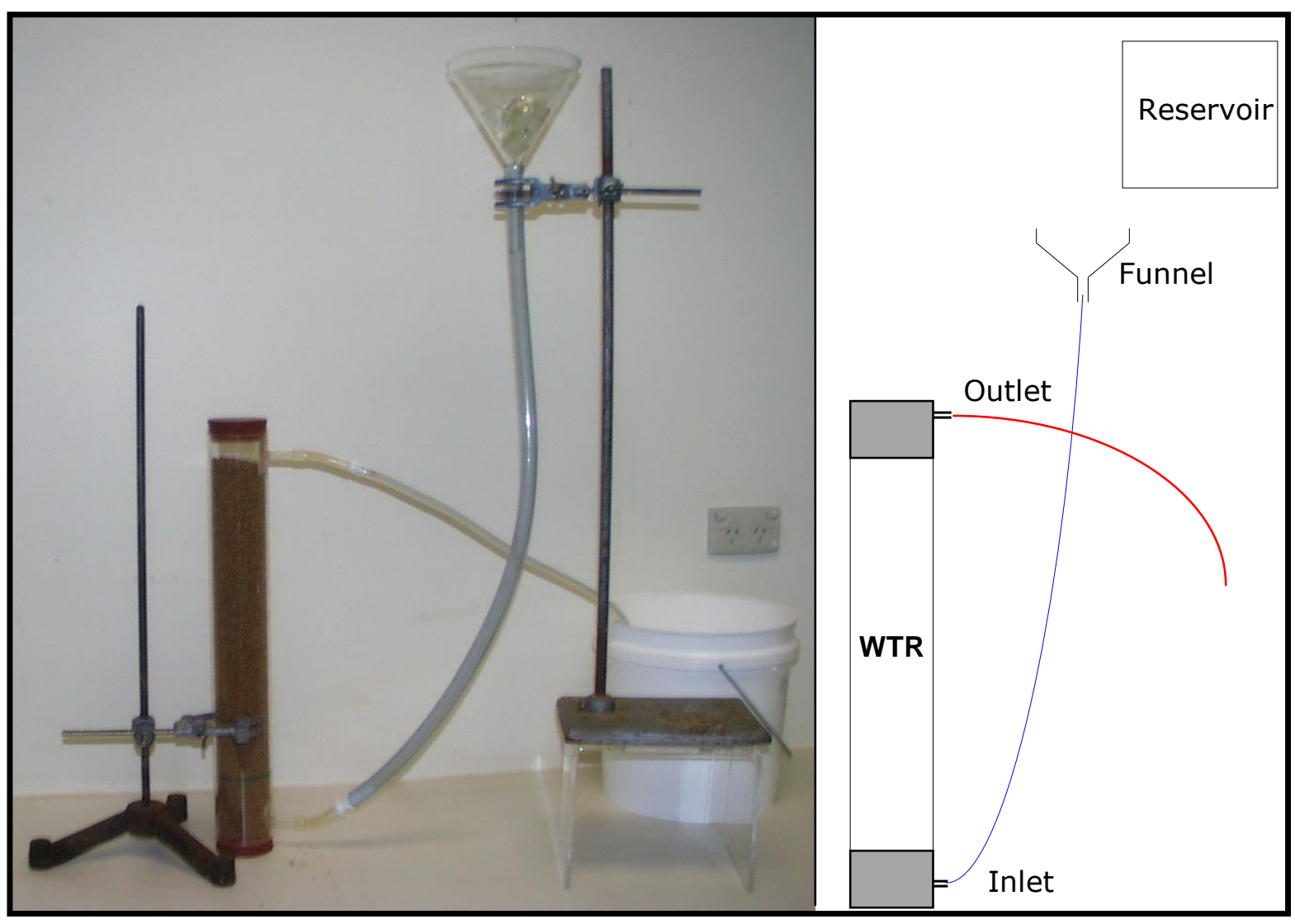

Figure 2. Photograph and schematic of system used to load WTR with $P$, showing $P$ solution reservoir, funnel and cylinder containing WTRs. 
Oliver IW, Grant CD, Murray RS. Assessing effects of aerobic and anaerobic conditions on phosphorus sorption and retention capacity of water treatment residuals. Journal of Environmental Management 2011; 92: 960-966.

DOI: 10.1016/j.jenvman.2010.11.016 (this file includes supplementary information and 2015 corrigendum)

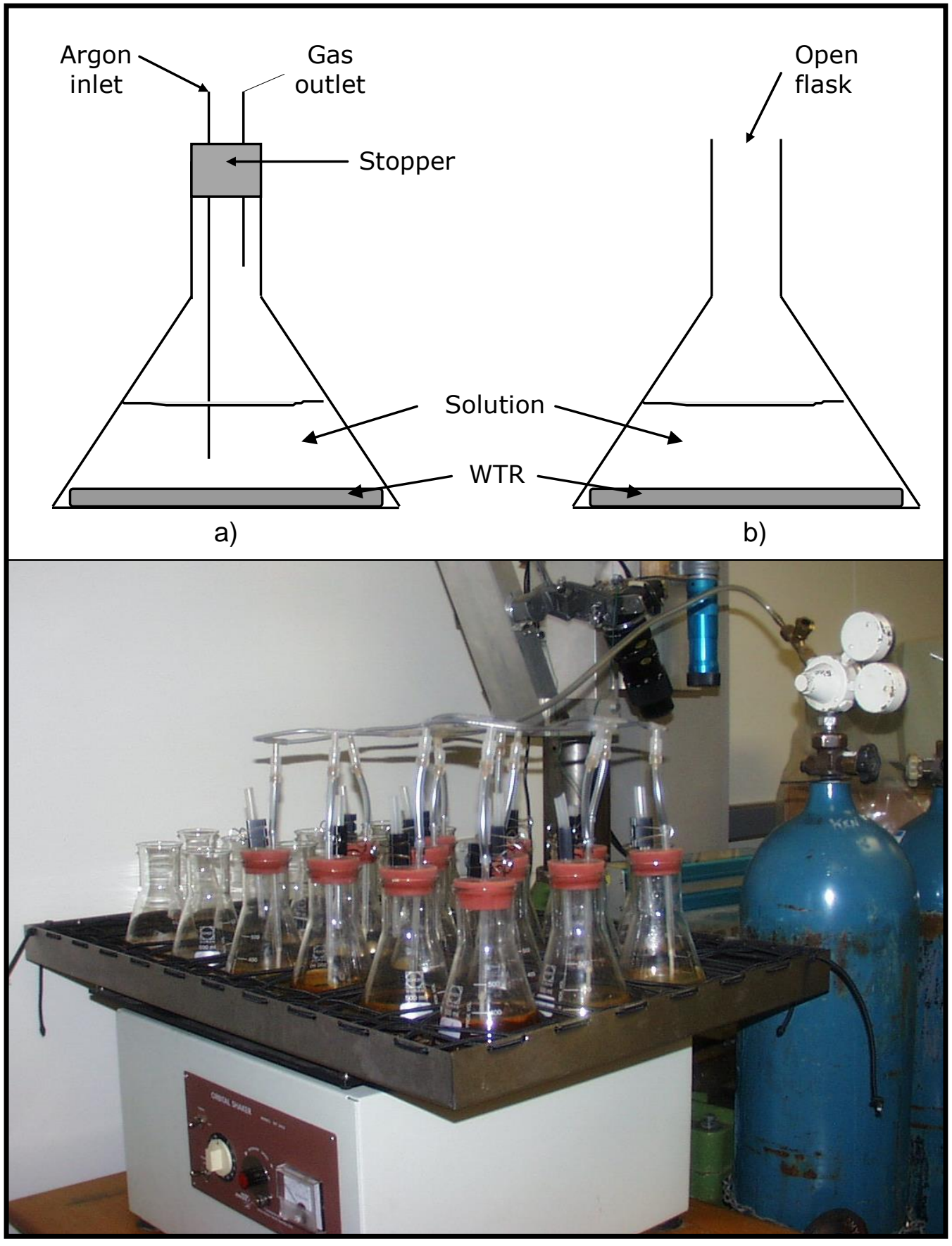

Figure 3. Apparatus for exposing WTRs to a) anaerobic conditions, and b) aerobic conditions. Photograph also shows Ar gas manifold and orbital shaking device. 

retention capacity of water treatment residuals. Journal of Environmental Management 2011; 92: 960-966.

DOI: 10.1016/j.jenvman.2010.11.016 (this file includes supplementary information and 2015 corrigendum)

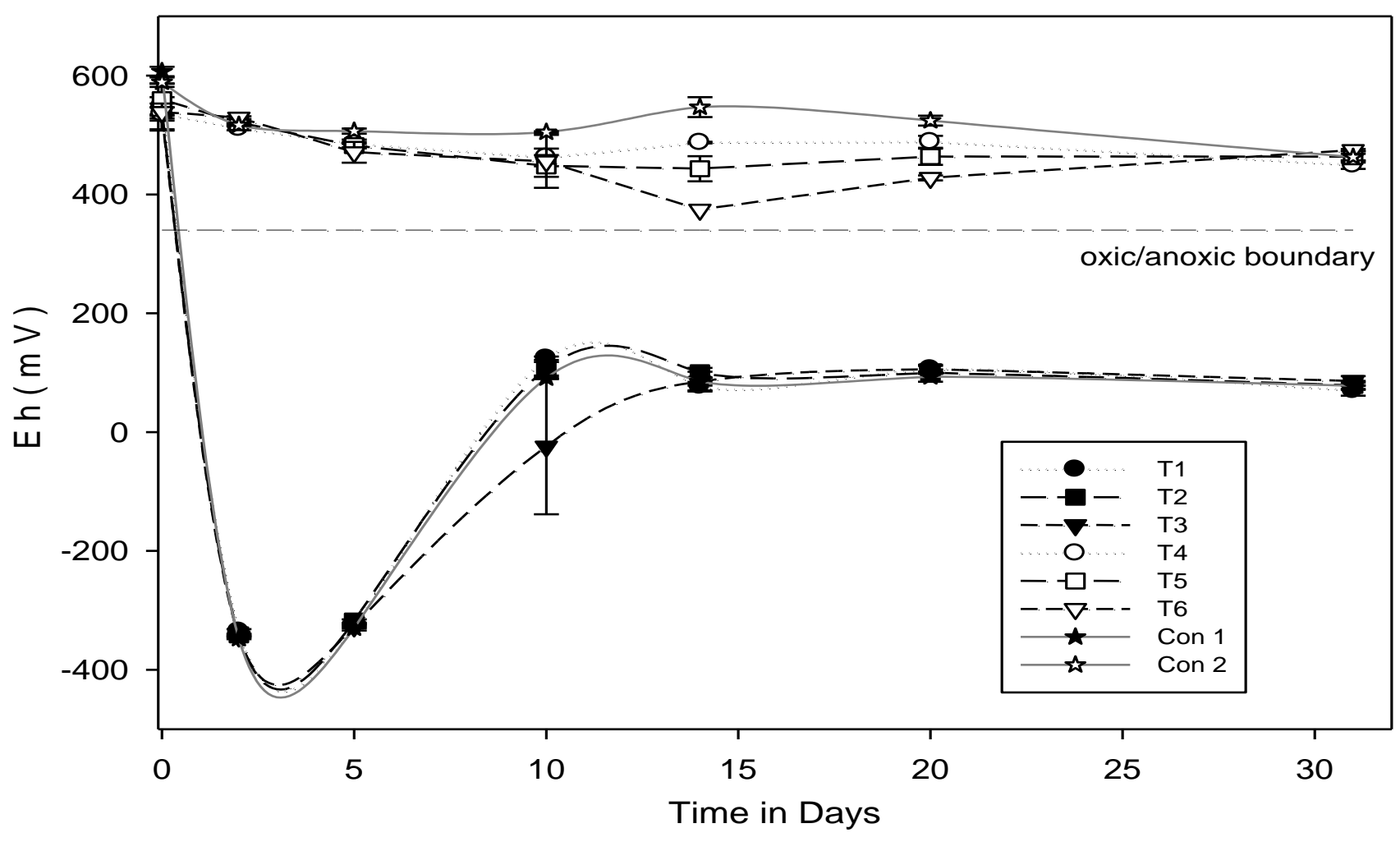

Figure 4. Redox potential, Eh, of treatments. Error bars, where they extend beyond symbol margins, indicate standard error $(n=3)$. The horizontal line indicates the oxic (above)/ anoxic (below) boundary according to Patrick and Mahapatra (1968). 
Oliver IW, Grant CD, Murray RS. Assessing effects of aerobic and anaerobic conditions on phosphorus sorption and retention capacity of water treatment residuals. Journal of Environmental Management 2011; 92: 960-966.

DOI: 10.1016/j.jenvman.2010.11.016 (this file includes supplementary information and 2015 corrigendum)

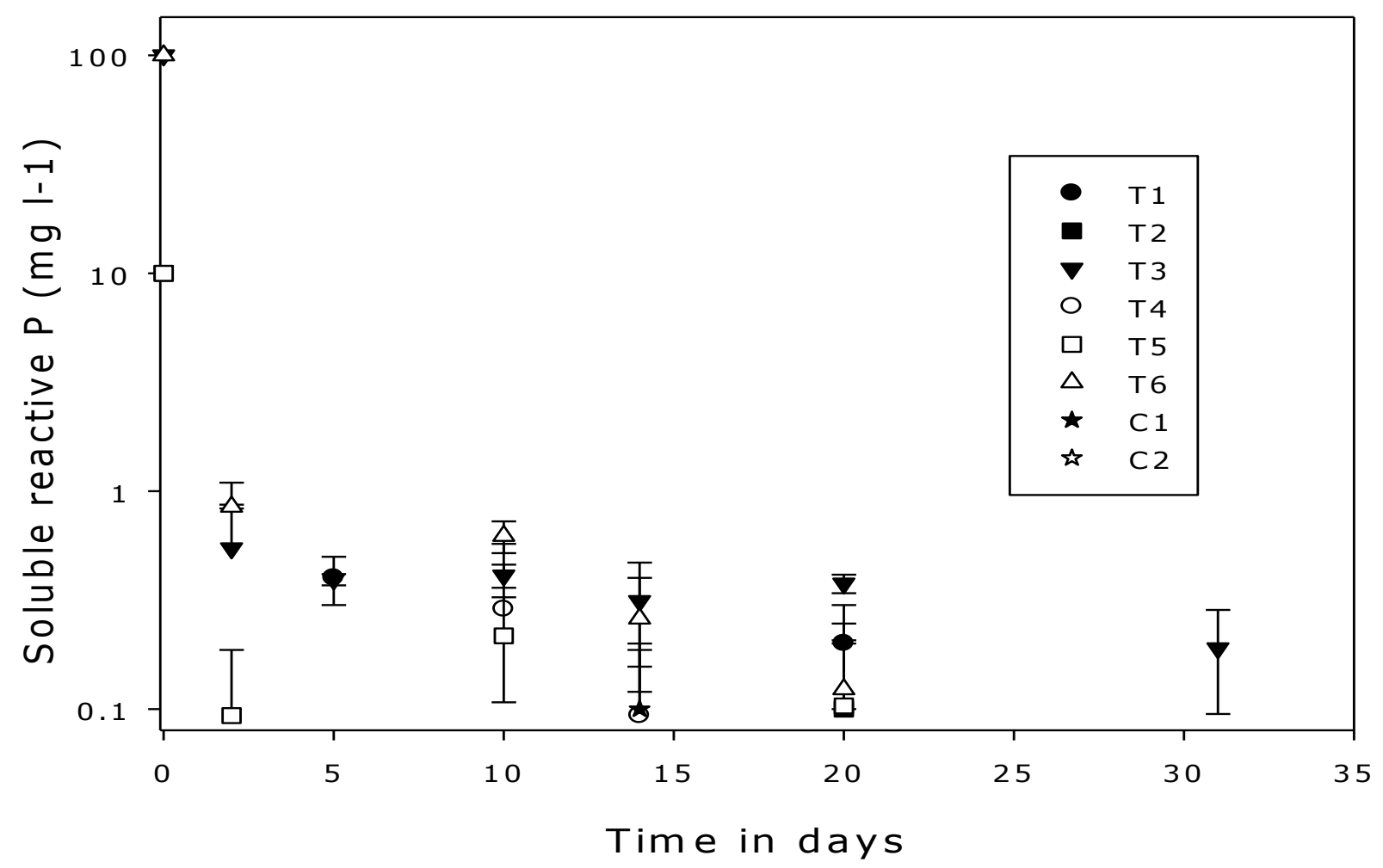

Figure 5. Soluble reactive $P$ concentration in supernatant solutions. Error bars, where they extend beyond symbol margins, indicate standard error. Note logarithmic y-axis scale. 
Oliver IW, Grant CD, Murray RS. Assessing effects of aerobic and anaerobic conditions on phosphorus sorption and retention capacity of water treatment residuals. Journal of Environmental Management 2011; 92: 960-966.

DOI: 10.1016/j.jenvman.2010.11.016 (this file includes supplementary information and 2015 corrigendum)

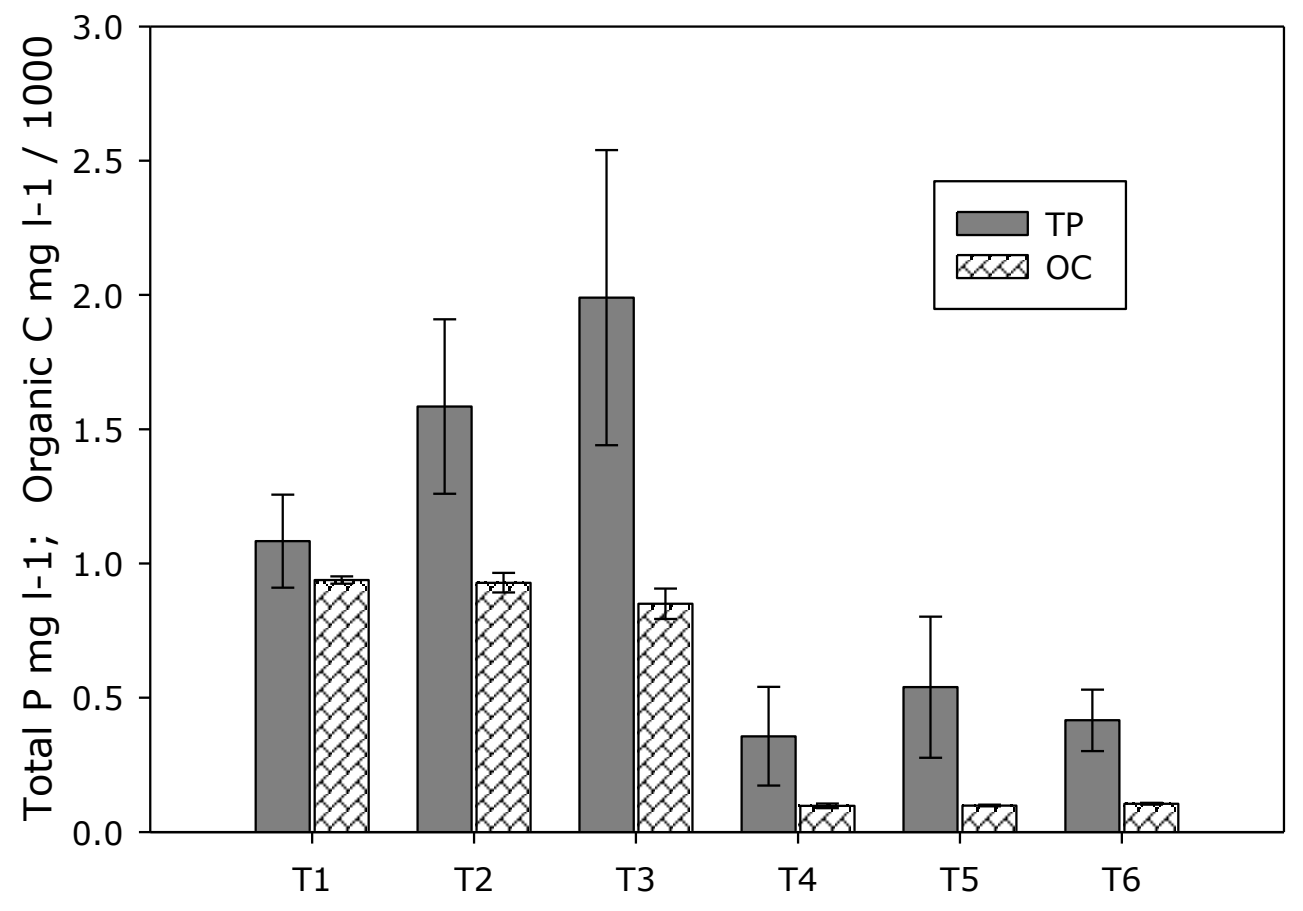

Figure 6. Total $\mathrm{P}\left(\mathrm{mg} \mathrm{l}^{-1}\right)$ and organic $\mathrm{C}\left(\mathrm{mg} \mathrm{l}^{-1} / 1000\right)$ concentrations in supernatant solutions after 31 days. Error bars indicate standard error. 

retention capacity of water treatment residuals. Journal of Environmental Management 2011; 92: 960-966.

DOI: 10.1016/j.jenvman.2010.11.016 (this file includes supplementary information and 2015 corrigendum)

Table 1: Selected physical \& chemical properties of ferric WTR (Macks 1997)

\begin{tabular}{lc}
\hline Aggregate Density $\left(\mathrm{g} / \mathrm{cm}^{3}\right)$ & 1.6 \\
Porosity & 0.38 \\
Surface Area, m$~^{2} \mathrm{~g}^{-1}$ & 232 \\
Total $\mathrm{Fe}, \mathrm{mg} \mathrm{kg}^{-1}$ & 82263 \\
Total Al, $\mathrm{mg} \mathrm{kg}^{-1}$ & 72300 \\
Total $\mathrm{P}, \mathrm{mg} \mathrm{kg}^{-1}$ & 1339 \\
Total $\mathrm{Mn}, \mathrm{mg} \mathrm{kg}^{-1}$ & 6685 \\
Total $\mathrm{Ca}, \mathrm{mg} \mathrm{kg}^{-1}$ & 17005 \\
Total $\mathrm{Na}, \mathrm{mg} \mathrm{kg}^{-1}$ & 749 \\
Total $\mathrm{C}, \%$ & 5.7 \\
Total $\mathrm{N}, \%$ & 0.61 \\
Total $\mathrm{Cl}, \mathrm{mg} \mathrm{kg}^{-1}$ & 425 \\
$\mathrm{pH}_{1: 5}$ water & 7.3 \\
\hline
\end{tabular}

Table 2. Treatments imposed $(n=3)$

\begin{tabular}{ccc}
\hline Treatment & $\begin{array}{c}\text { Solution [P], } \\
\mathrm{mg} \mathrm{I}^{-1}\end{array}$ & Condition \\
\hline 1 & 0 & Anaerobic \\
2 & 10 & Anaerobic \\
3 & 100 & Anaerobic \\
4 & 0 & Aerobic \\
5 & 10 & Aerobic \\
6 & 100 & Aerobic \\
$\mathrm{C1}^{*}$ & 0 & Anaerobic \\
$\mathrm{C}^{*}$ & 0 & Aerobic \\
\hline${ }^{*}$ control WTR (i.e. not loaded with P)
\end{tabular}



retention capacity of water treatment residuals. Journal of Environmental Management 2011; 92: 960-966.

DOI: 10.1016/j.jenvman.2010.11.016 (this file includes supplementary information and 2015 corrigendum)

\section{Supplementary Information}

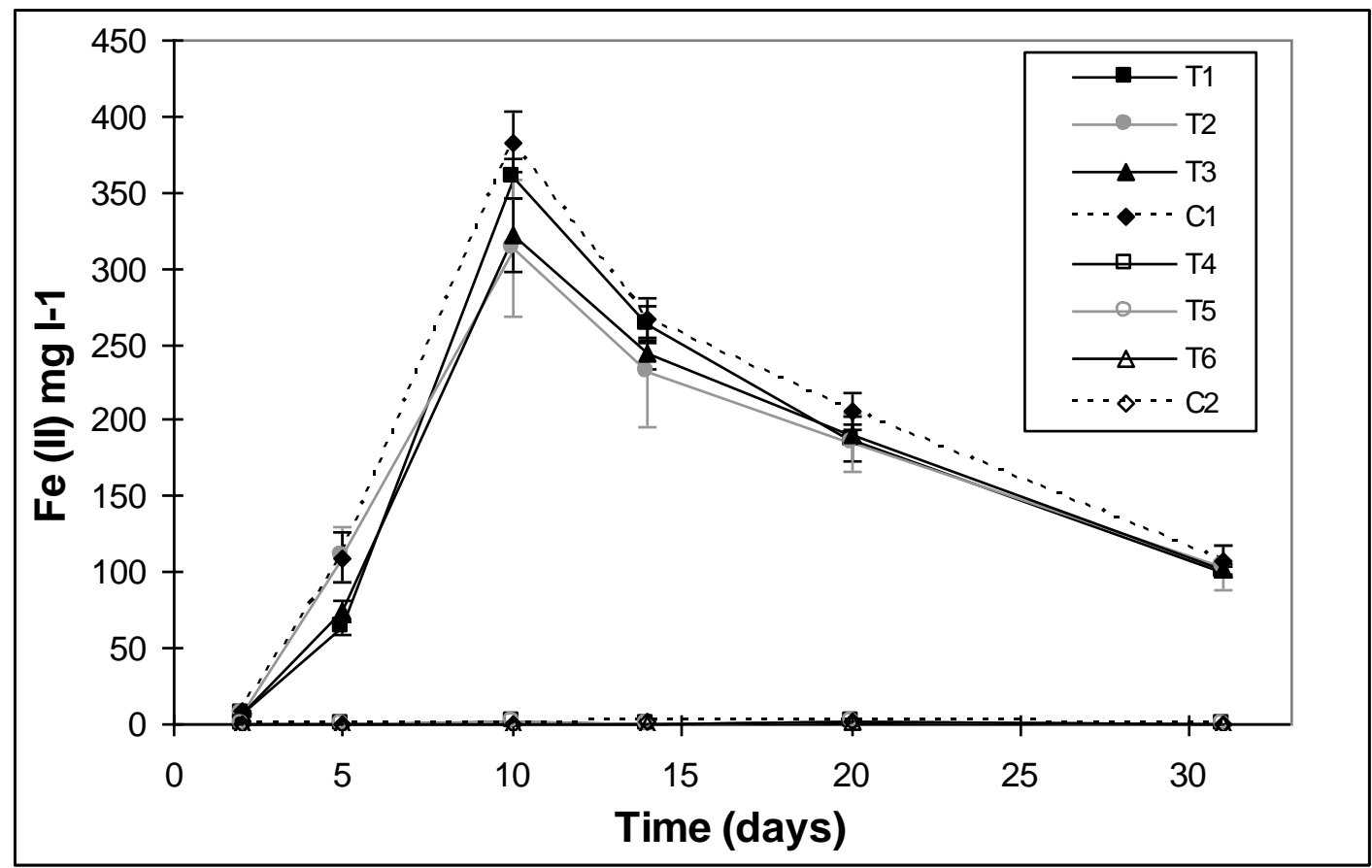

Supplementary Figure 1. Iron (II) concentrations in supernatant solutions. Note that aerobic treatments (treatment 4,5,6 and control 2) had iron (II) concentrations below detection, while all anaerobic treatments $(1,2,3)$ and the anaerobic control (C1) had iron (II) concentrations above $100 \mathrm{mg} \mathrm{l}^{-1}$. 


\title{
Construction of Stoppers for Anaerobic Treatments
}

\author{
$\underline{\text { Materials }}$
}

\begin{tabular}{|l|l|}
\hline Rubber stopper & $52 \mathrm{~mm}$ top diameter, $48 \mathrm{~mm}$ base diameter \\
\hline Acrylic tubing (solid) & $3 \mathrm{~mm}$ internal diameter (ID), $6 \mathrm{~mm}$ outer diameter (OD) \\
\hline Acrylic tubing (solid) & $2 \mathrm{~mm}$ ID, $3 \mathrm{~mm}$ OD \\
\hline Plastic tubing (flexible) & $6 \mathrm{~mm}$ ID, $8 \mathrm{~mm}$ OD \\
\hline Silicon tubing (flexible) & $6 \mathrm{~mm}$ ID, $10 \mathrm{~mm}$ OD \\
\hline Plastic ‘T' piece & $4 \mathrm{~mm} \mathrm{ID,7} \mathrm{mm} \mathrm{OD}$ \\
\hline Syringe needle & $0.5 \times 16 \mathrm{~mm}$ \\
\hline Bulldog clip & \\
\hline
\end{tabular}

\section{$\underline{\text { Construction }}$}

Rubber stoppers were shaped on a lathe to fit securely into the neck of flasks. Two holes were drilled through each stopper, with a $7.3 \mathrm{~mm}$ drill-bit, to accommodate gas inlet and outlet tubes.

The inlet tube was constructed using a $140 \mathrm{~mm}$ length of the $3 \mathrm{~mm}$ ID acrylic tubing, into which a $60 \mathrm{~mm}$ length of the $2 \mathrm{~mm}$ ID acrylic tubing was inserted (to a distance of approximately $5 \mathrm{~mm}$ ). The tube was then forced through one of the holes in the stopper (from the base), so that approximately $30 \mathrm{~mm}$ protruded from the top. An $80 \mathrm{~mm}$ length of plastic tubing was attached to the protruding portion. A syringe needle was then inserted into the opposite end of the plastic tubing (to regulate Ar flow at a slow and steady rate that would be consistent across all anaerobic treatments). A $40 \mathrm{~mm}$ length of flexible silicon tubing was then stretched over the end of the plastic tube housing the needle, into which a plastic ' $\mathrm{T}$ ' piece was inserted (to allow connection of the inlet tube to the Ar distribution system).

The outlet tube consisted of a $100 \mathrm{~mm}$ length of the $3 \mathrm{~mm}$ ID acrylic tubing, which was pushed through the second hole in the stopper so that approximately $20 \mathrm{~mm}$ protruded out of the top. A $60 \mathrm{~mm}$ length of silicon tubing was attached, enabling the outlet tube to be sealed by folding and clamping the silicon tube with a bulldog clip. Figure A.1 displays the stopper-gas tube design. 
Oliver IW, Grant CD, Murray RS. Assessing effects of aerobic and anaerobic conditions on phosphorus sorption and retention capacity of water treatment residuals. Journal of Environmental Management 2011; 92: 960-966.

DOI: 10.1016/j.jenvman.2010.11.016 (this file includes supplementary information and 2015 corrigendum)

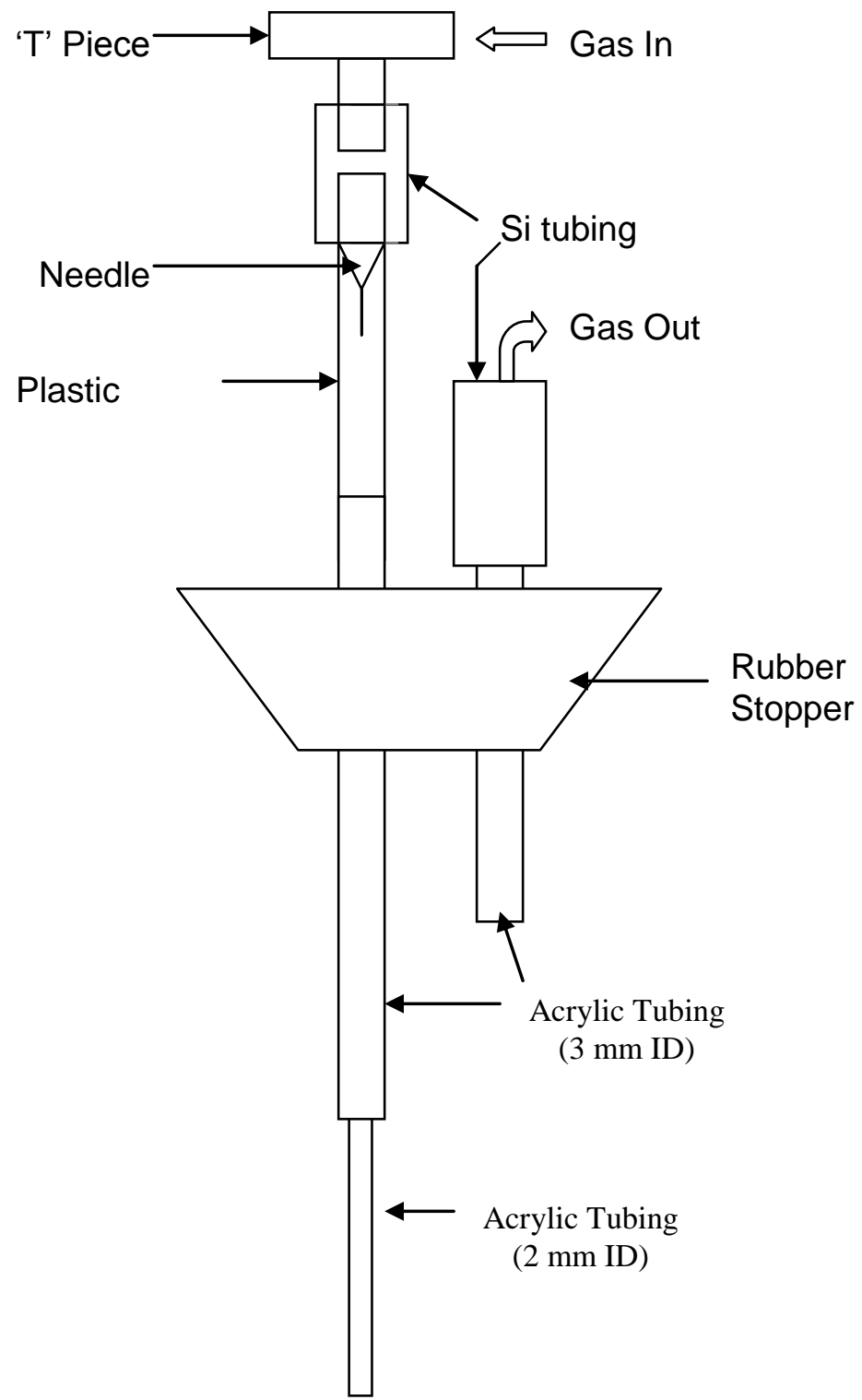

Figure Supp 2: Stopper design for anaerobic treatments 